\title{
EQUILIBRIUM IN THE SYSTEM: MERCURIC IODIDE AND ANILINE
}

\author{
BY J. N. PEARCE AND E. J. FRY
}

Those who have worked with aniline have no doubt observed its extraordinary high solvent power upon many of the inorganic salts. Like ammonia it also has the power of combining with the salts to form stable crystalline compounds containing from one to as high as six molecules of aniline of crystallization.

Among the large number of these crystalline compounds which have been prepared are $\mathrm{CoCl}_{2} .2 \mathrm{C}_{6} \mathrm{H}_{7} \mathrm{~N}, \mathrm{NiCl}_{2} .2 \mathrm{C}_{6} \mathrm{H}_{7} \mathrm{~N}$, ${ }^{1}$ $\mathrm{Cu}_{2} \mathrm{Cl}_{2.2} \mathrm{C}_{6} \mathrm{H}_{7} \mathrm{~N}, \quad \mathrm{Cu}_{2} \mathrm{Br}_{2} .2 \mathrm{C}_{6} \mathrm{H}_{7} \mathrm{~N}, \quad \mathrm{Cu}_{2} \mathrm{I}_{2} .2 \mathrm{C}_{6} \mathrm{H}_{7} \mathrm{~N} .^{2}$ Tombeck ${ }^{3}$ prepared the corresponding compounds of the chlorides, bromides, iodides and nitrates of zinc and cadmium and of magnesium nitrate. He also prepared similar compounds of zine, cadmium, magnesium, nickel, cobalt and copper sulphates, all of which combine with two molecules of aniline except nickel sulphate which crystallizes with six molecules and cobalt sulphate which crystallizes with four molecules of aniline. Grossman and Hunter ${ }^{4}$ prepared the compounds of the thiocyanates of cadmium, cobalt, nickel, iron, manganese and zinc, each combining with two molecules of the base. The dichromates of cobalt, nickel, copper, cadmium, zinc and manganese, each with four molecules of aniline were made by Parravaus and Pasta. ${ }^{5}$ Françoise $^{6}$ contributed the compounds with the mercuric halides, each with two molecules of aniline of crystallization.

The usual method of preparing these compounds has been to treat alcoholic solutions of the salt with aniline, or vice versa.

${ }^{1}$ Lippmann and Vortmann: Ber. chem. Ges. Berlin, I2, 79 (1889).

2Saglier: Comptes rendus, I06, 1422.

${ }^{3}$ Ibid., I24, 96 I; x26, 967.

${ }^{4}$ Zeit. anorg. Chern., 46, 36I (1903).

' Gazz. chim. Ital., 37 II, 252 (1907).

'Jour. pharm. Chem., 6, 2 I (Igo6). 
Only one system containing aniline and an inorganic salt has been studied quantitatively. This was done by Menschutkin ${ }^{1}$ for the system: magnesium bromide and aniline. These two substances react with the liberation of much heat and produce three compounds. The temperaturesolubility equilibrium curve consists of three parts, viz., $\mathrm{MgBr}_{2}, 6 \mathrm{C}_{6} \mathrm{H}_{7} \mathrm{~N}$ in equilibrium with its saturated solution at all temperatures up to $103^{\circ}$; that of $\mathrm{MgBr}_{2.4} \mathrm{C}_{6} \mathrm{H}_{7} \mathrm{~N}$ between IO $3^{\circ}$ and $237^{\circ}$; and probably the compound $\mathrm{MgBr}_{2} \cdot 2 \mathrm{C}_{6} \mathrm{H}_{7} \mathrm{~N}$ or $\mathrm{MgBr}_{2} \cdot \mathrm{C}_{6} \mathrm{H}_{7} \mathrm{~N}$ at still higher temperatures. Owing to the decomposition of the aniline the investigation could not be carried higher than $25^{\circ}$.

Owing to the relatively high solubility of mercuric iodide in aniline at ordinary temperatures, the dimorphic nature of the solid iodide and the power of the two to form stable crystalline compounds, it was thought worth while to make a careful study of this system over the maximum possible range of temperature. For this purpose the ordinary solubility method has been used.

Kahlbaum's aniline "I" was allowed to stand over fused potassium hydroxide for two weeks, then decanted and carefully distilled. Only that fraction passing over at $180^{\circ}-182^{\circ}$ was collected for the work, the first and last portions being rejected.

The mercuric iodide was precipitated from a saturated solution of chemically pure mercuric chloride by means of an equivalent weight of pure potassium iodide. The precipitate was allowed to settle and then washed by decantation, using large volumes of distilled water, until all traces of chlorine were removed. It was then transferred to a large Büchner funnel, washed with distilled water, sucked dry and finally spread upon porous plates and thoroughly dried.

The solubility measurements were made in an apparatus similar to the one used by Pearce and Moore. ${ }^{2}$

${ }^{1}$ Gazz. chim. Ital., 37, I, 252 (1907).

${ }^{2}$ Am. Chem. Jour., 50, 220 (I9I3). 
For all temperatures between $0^{\circ}$ and $42.9^{\circ}$ an electrically heated and electrically controlled water thermostat was used; a cooling coil for runining water was added for temperatures below that of the room. In this way temperatures constant to within $=0.02^{\circ}$ could be maintained for any desired period of time. For temperatures above $42.9^{\circ}$ the saturation tube was immersed in the vapor of a boiling liquid whose boiling point was approximately equal to the temperature desired. The tube containing the motor-driven spiral was inserted through a tightly fitting cork into a larger boiling vessel to the side tubule of which was fitted a long vertical condenser to prevent the loss of the boiling liquid by evaporation. The liquid was maintained at the boiling temperature by means of an electrically heated platinum spiral. In order to prevent variation in temperature due to radiation, which increases with the temperature, the whole apparatus, excepting the condenser, was inclosed in an asbestos case fitted with a glass door through which the temperature readings could be taken. In order to still further prevent the loss of heat by radiation, the inside of the case was heated by means of incandescent lights. By this means even the highest temperatures could be kept constant to within $\pm 0.05^{\circ}$, any variation being due to changes in barometric pressure only.

For temperatures below $0^{\circ}$ the saturation tube and stirrer were transferred to a larger tube which was surrounded by a freezing mixture of ice and salt. All temperatures were read on a certified thermometer passing through the cork and kept at the same level as the material in the saturation tube. The thermometers were graduated in $0.10^{\circ}$ which easily permitted estimations accurate to $=0.05^{\circ}$.

Repeated tests showed that saturation was complete in about one and one-half hours. In most cases, however, the time allowed for saturation was much longer, except at the three highest temperatures where, owing to decomposition, the time had to be limited.

After saturation was complete the stirrer was stopped, the solid phase allowed to settle and a sample of the liquid 
phase was removed by means of a small tube covered at one end by a double thickness of thin muslin. In order to prevent solidification within the tube the latter was heated to a temperature slightly higher than that of the saturated solution. All samples were run at once into dry glass-stoppered weighing bottles and kept in dry desiccators until analyzed.

The difficulties in the analysis of either phase of the system are readily appreciated when one considers the volatile nature of the iodide and its inertness toward ordinary reagents. The complications are still further increased by the difficulty in eliminating the easily oxidized aniline and its oxidation products.

Obviously the simplest method would be to remove the aniline by means of organic solvents and weigh the iodide directly, but this is impossible on account of the appreciable solubility of the mercuric iodide in these solvents. An attempt was made to dissolve out the aniline with dilute hydrochloric acid, but here also the iodide was found to be appreciably soluble in the aniline hydrochloride formed. Likewise the electrolytic method was found to be unsatisfactory because of the formation of aniline black at the anode. This was deposited upon the surface of the mercury and the exposed platinum and could not be removed.

The method finally adopted was to dissolve the sample in a solution of acetic acid containing an excess of potassium iodide and to precipitate the mercury as the sulphide by passing in hydrogen sulphide to complete precipitation. This method proved to be very satisfactory and was used in all determinations.

Samples taken at the three highest temperatures seemed to be more difficultly soluble and complete transformation to the sulphide was accomplished by placing the solid mass in the acetic acid-potassium iodide solution and passing hydrogen sulphide for two or three hours until portions of the - filtrate gave no test for mercury on further treatment with hydrogen sulphide. The precipitate was then transferred to a weighed Gooch crucible, washed with water and absolute 
alcohol and then gently dried. The free sulphur was removed by carbon bisulphide in an electrically heated extraction apparatus of the form recommended by Treadwell and Hall. ${ }^{1}$

The quantities of acetic acid or potassium iodide added did not seem to affect the speed of transformation of the iodide to the sulphide, but the physical nature of the precipitate was considerably improved, if the system was heated slightly before filtration.

The sulphur-free precipitate was then placed in an air bath and heated to $110^{\circ}$, the temperature recommended by Treadwell and Hall. The weights obtained after successive heatings were found to decrease constantly with the time of heating. Believing that this inconstancy is due to the volatilization of the sulphide, experiments were made to test the effect of temperature upon the extent of volatilization of the sulphide. Weighed Gooch crucibles containing the pure dry sulphides were heated for intervals of one to three hours at $70^{\circ}, 80^{\circ}$ and $110^{\circ}$. The results are recorded in Table $I$.

TABLE I

\begin{tabular}{|c|c|c|}
\hline$\underset{\text { Grams }}{\mathrm{HgS}}$ & One hour at $110^{\circ}$ & Two hours at $110^{\circ}$ \\
\hline \multirow[t]{2}{*}{$\begin{array}{l}\text { I. } 435^{2} \\
2.3076 \\
\end{array}$} & $\begin{array}{l}\text { I. } 4202 \\
2.232 \text { I } \\
\end{array}$ & $\begin{array}{r}1.2784 \\
2.0375 \\
\end{array}$ \\
\hline & Two hours at $80^{\circ}$ & Three hours at $80^{\circ}$ \\
\hline \multirow[t]{2}{*}{$\begin{array}{l}0.5412 \\
0.6879 \\
\end{array}$} & $\begin{array}{l}0.5378 \\
0.6765 \\
\end{array}$ & $\begin{array}{l}0.5300 \\
0.6685 \\
\end{array}$ \\
\hline & One hour at $70^{\circ}$ & Three hours at $70^{\circ}$ \\
\hline $\begin{array}{l}0.43 \text { II } \\
0.4432 \\
0.2054 \\
0.1802\end{array}$ & $\begin{array}{l}\text { o. } 43 \text { I I } \\
\text { O. } 4432 \\
\text { o. } 2054 \\
\text { o. I } 801\end{array}$ & $\begin{array}{l}0.43 \text { I I } \\
0.443 \text { I } \\
0.2054 \\
\text { o. I } 80 \text { I }\end{array}$ \\
\hline
\end{tabular}

1 "Analytical Chemistry," Vol. II, third edition, p. I69. 
All the data in the following tables were obtained by heating the precipitates to constant weight at $70^{\circ}$. By observing these precautions results were obtained which leave little to be desired as to the accuracy of the method. Analyses made on known weights of mercuric iodide in aniline gave the following results:

TABLE II

\begin{tabular}{c|c} 
Grams taken & Grams found \\
\hline 0.4325 & 10.4323 \\
0.2936 & 0.2930 \\
0.5872 & 0.5872
\end{tabular}

The results of the solubility determinations made in this work are given in Table III and they are graphically represented by the Curve, Fig. r.

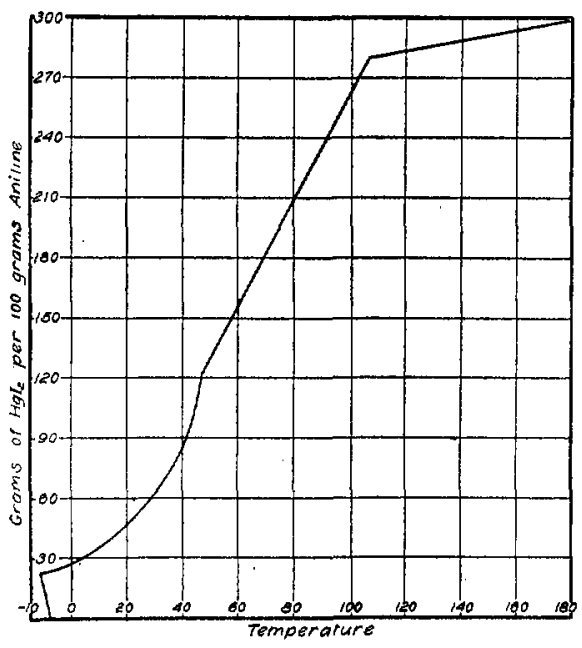

Fig. I

The freezing point of aniline, purified according to the * method of Hantzsch, was found by one of us ${ }^{1}$ to be $-8^{\circ} \mathrm{C}$,

1 Pearce. 
TABLE III

\begin{tabular}{|c|c|c|c|c|c|}
\hline Temp. & $\begin{array}{l}\text { Solution } \\
\text { phase } \\
\text { Grams }\end{array}$ & $\mathrm{HgS}$ & $\mathrm{HgI}_{2}$ & $\begin{array}{l}\text { Gr. } \mathrm{HgI}_{2} \\
\text { per Ioo gr. } \\
\text { of aniline }\end{array}$ & Mean \\
\hline$-6.5^{\circ}$ & 4.0110 & 0.3910 & 0.7636 & $23 \cdot 5^{2}$ & \multirow{3}{*}{$23 \cdot 35$} \\
\hline-6.5 & 3.7128 & 0.3667 & 0.7162 & $23 \cdot 10$ & \\
\hline-6.5 & 3.8273 & 0.3719 & 0.7264 & $23 \cdot 4^{2}$ & \\
\hline+0.4 & I. 3666 & 0.2054 & 0.4012 & 28.72 & \multirow{3}{*}{28.69} \\
\hline 0.4 & 2.8167 & 0.3214 & 0.6277 & 28.68 & \\
\hline 0.4 & I. 5798 & O. I 802 & 0.3519 & 28,66 & \\
\hline I 7.8 & 2.8032 & 0.43 II & 0.8420 & 42.94 & \multirow{3}{*}{42.85} \\
\hline I 7.8 & $2.88 \mathrm{I} 8$ & 0.4432 & 0.8670 & 42.80 & \\
\hline 17.8 & 2.8667 & 0.4396 & 0.8586 & $42.8 I$ & \\
\hline 21.10 & 3.0095 & 0.4937 & 0.9867 & $47 \cdot 43$ & \multirow{2}{*}{$47 \cdot 55$} \\
\hline $2 \mathrm{I}, \mathrm{I}$ & 2.7408 & o. 4543 & 0.8848 & 47.67 & \\
\hline 26.9 & $3 \cdot 7408$ & 0.6842 & I. 3365 & $55 \cdot 5^{8}$ & \multirow{2}{*}{$55 \cdot 47$} \\
\hline 26.9 & 2.7353 & 0.4987 & 0.9707 & $55 \cdot 35$ & \\
\hline 30.1 & $3 \cdot 5303$ & 0.6927 & I. 3530 & 62.14 & \multirow{2}{*}{62.05} \\
\hline 30.1 & $3 \cdot 3077$ & 0.6478 & I. 2650 & 61.96 & \\
\hline 36.2 & 2.4979 & 0.55 I 2 & I. 0770 & $75 \cdot 76$ & \multirow{3}{*}{75.80} \\
\hline 36.2 & 2.9044 & 0.6456 & $\mathrm{I} .26 \mathrm{IO}$ & 76.03 & \\
\hline 36.2 & 3. I 347 & 0.6879 & I. 3435 & $75 \cdot 7^{2}$ & \\
\hline 42.9 & 3.2802 & 0.8204 & 1.6025 & 96.60 & \multirow{3}{*}{96.49} \\
\hline 42.9 & $3 \cdot 4225$ & 0.8604 & I. 6805 & 96.47 & \\
\hline $42 \cdot 9$ & $3 \cdot 5057$ & $0.88 \mathrm{I} 2$ & I. 7210 & 96.40 & \\
\hline 48.8 & 3.6347 & I . 0447 & 2.0480 & I 28.4 & \multirow{3}{*}{ I $28 . \mathrm{I}$} \\
\hline 48.8 & 3.6440 & I. 0509 & 2.0530 & 128.0 & \\
\hline 48.8 & $3.800 \mathrm{I}$ & I.09OI & 2. I 290 & 127.9 & \\
\hline 63.6 & 2.4242 & 0.7680 & I. 5000 & I 62.9 & \multirow{3}{*}{163.8} \\
\hline 63.6 & 2.0912 & 0.6652 & I . 2990 & 164.0 & \\
\hline 63.6 & 2.1322 & 0.6833 & I. $335^{\circ}$ & 163.6 & \\
\hline 70.82 & $7 \cdot 4980$ & 2.4870 & 4.8580 & I 84.0 & \multirow{2}{*}{$\mathrm{I} 84 \cdot \mathrm{I}$} \\
\hline 70.82 & $7 \cdot 4982$ & 2.4890 & 4.8600 & I 84.2 & \\
\hline 76.2 & $4 \cdot 3407$ & I. 49 IO & $2.9 \mathrm{I} 2 \mathrm{O}$ & $202 \cdot 5$ & \multirow{2}{*}{201.6} \\
\hline 76.2 & 3.6806 & I . 2586 & 2.4590 & 201.2 & \\
\hline $95 \cdot 9$ & I. 5092 & 0.5500 & I. .074 & 246.8 & \multirow{2}{*}{$246 \cdot 7$} \\
\hline $95 \cdot 9$ & I. 5092 & o. 5497 & 1.072 & 246.5 & \\
\hline I I $5 \cdot 7$ & 2.2309 & $0.845^{6}$ & I. 6520 & 28 I. 8 & \multirow{2}{*}{$28 \mathrm{I} .8$} \\
\hline I $15 \cdot 7$ & I .3955 & 0.5274 & I .0300 & $28 \mathrm{I} .8$ & \\
\hline I 37.2 & o. 6997 & 0.2648 & 0.5172 & 284.9 & \multirow[t]{2}{*}{285.2} \\
\hline I 37.2 & o. I 893 & 0.0720 & o. I 490 & 286.5 & \\
\hline I $8 \mathrm{I} . \mathrm{I}$ & 0.9820 & 0.3763 & $0.735^{\circ}$ & 297.6 & \multirow{2}{*}{297.9} \\
\hline I8I. I & $2.46 \mathbf{I} 2$ & 0.9823 & I. 9180 & 298.3 & \\
\hline $199 . I^{1}$ & 2.1435 & 0.9797 & I.9 I 40 & 862.5 & \multirow{2}{*}{863.2} \\
\hline I 99.1 & 0.7405 & 0.3384 & 0.6644 & 864.0 & \\
\hline
\end{tabular}

' Not plotted. 
a value identical with that found by Lucius. ${ }^{1}$ That part of the curve between $-8^{\circ}$ and $-\operatorname{Ir} .48^{\circ}$ represents the freezing point curve for the solution in equilibrium with solid aniline.

At $-\mathrm{I}$ I. $48^{\circ}$ solid aniline and the compound $\mathrm{HgI}_{2} .2 \mathrm{C}_{6} \mathrm{H}_{7} \mathrm{~N}$ separate out together in the form of a eutectic mixture. This point was determined three times by plotting the cooling curve of the saturated solution. In a freezing point tube fitted with a thermometer and stirrer and surrounded by an air jacket was placed the saturated solution. The whole was placed in a freezing mixture of ice and salt $\left(-16^{\circ}\right)$ and gently stirred until a slight undercooling was obtained. The temperature then quickly rose to the eutectic point where it remained constant until the entire mass had solidified and then fell slowly to the temperature of the bath. The points obtained were -II. $5^{\circ},-\mathrm{II} .55^{\circ}$ and $\mathrm{II} .4^{\circ}$, the mean being -II.48 $3^{\circ}$.

Beginning with the eutectic point the solubility of the mercuric iodide increases gradually up to about $10^{\circ}$ and then at a more rapidly increasing rate up to $46.8^{\circ}$. The white crystalline solid in equilibrium with the saturated solution has the composition $\mathrm{HgI}_{2} .2 \mathrm{C}_{6} \mathrm{H}_{7} \mathrm{~N}$. Its melting point is $58.6^{\circ}$. These crystals have parallel cleavage and parallel extinction; they belong to the third or fourth system, but it was impossible to determine exactly which.

At $46.8^{\circ}$ we have a quadruple point representing an equilibrium between the two solids, $\mathrm{HgI}_{2}, \mathrm{HgI}_{2} .2 \mathrm{C}_{6} \mathrm{H}_{7} \mathrm{~N}$, the saturated solution and aniline vapor.

From this point on the solubility curve rises rapidly and linearly with rise in temperature up to $108^{\circ}$, the solid phase in equilibrium being the red mercuric iodide. At $108^{\circ}$ we have a second quadruple point, the solids being the red and yellow mercuric iodides in equilibrium with the saturated solution and vapor. The transition point between the red and the yellow iodides is apparently lowered by the influence of the solvent from $126^{\circ}$ to $108^{\circ}$. This is in accord with the

1 Ber. chem. Gẹs. Berlin, 5, 154 (1872). 
work done by $\mathrm{Kastle}^{1}$ in which he finds that the transition point of the iodide is affected by the solvent used.

An insoluble greenish yellow solid begins to appear at about this temperature and the solution assumes a violet permanganate color.

Above $108^{\circ}$ the solubility of the yellow iodide increases but slightly up to approximately $200^{\circ}$. Beyond this point the highly viscous liquid phase seemed to be in equilibrium with the solid yellow mercuric iodide. The entire mass solidified to a pasty solid on cooling which on standing gradually passed over into the crystalline form. On account of the rapid decomposition of the components at these high temperatures further measurements were entirely out of question.

The insoluble solid coming in at $108^{\circ}$ and above was isolated, thoroughly washed with acidulated water and alcohol. It is a greenish yellow, flaky, mica-like solid belonging to the fifth or sixth system. It is insoluble in water, alcohol, hot aniline, or the ordinary acids, but dissolves with decomposition in potassium cyanide, liberating free mercury. Its analysis was difficult. Small weighed samples of the clean solid were placed in a weighed platinum dish and the mercury determined electrolytically. Weighed quantities of the solid were also added to strongly acidified solutions of silver nitrate, the suspension was heated and then allowed to stand until transformation was complete. From the weights of the silver iodide precipitated the approximate percent of iodine was calculated. The percentages of mercury and iodine found correspond approximately with the values calculated for the undescribed compound, $\mathrm{C}_{6} \mathrm{H}_{7} \mathrm{~N} . \mathrm{Hg}_{2} \mathrm{I}_{2}, e . g$.,

\begin{tabular}{ccc} 
& $\begin{array}{c}\text { Found } \\
\text { Percent }\end{array}$ & $\begin{array}{c}\text { Calculated } \\
\text { Percent }\end{array}$ \\
$\mathrm{Hg}$ & 56.9 & $53 \cdot 77$ \\
$\mathrm{I}$ & 35.7 & 34.02 \\
& & \\
\hline Am, Chem. Jour., 22, 473 (1899). &
\end{tabular}




\section{Summary}

The system of mercuric iodide and aniline has been studied for temperatures between $-\mathrm{II} .48^{\circ}$ and $18 \mathrm{I}^{\circ}$ and the curve representing the conditions of equilibrium has been plotted.

The region of stability of the three solids, $\mathrm{Hg}_{\mathrm{I}} \mathrm{I}_{2} \cdot \mathrm{C}_{6} \mathrm{H}_{7} \mathrm{~N}$, red $\mathrm{HgI}_{2}$ and yellow $\mathrm{HgI}_{2}$, in the presence of aniline has been established.

A new compound corresponding to the formula $\mathrm{C}_{6} \mathrm{H}_{7} \mathrm{~N}$.$\mathrm{Hg}_{2} \mathrm{I}_{2}$ has been identified and described.

A method for the determination of mercuric iodide in the presence of an easily oxidized organic solvent has been tested and applied.

Physical Chemistry Laboratory

The State University of Iowa 